\section{Vasopressin and epinephrine versus epinephrine in management of patients with cardiac arrest: a meta-analysis}

\author{
XIAO-LI JING・DONG-PING WANG・XIN LI・HUI LI・ \\ XIAO-XING LIAO • YAN XIONG・XI-FU WANG
}

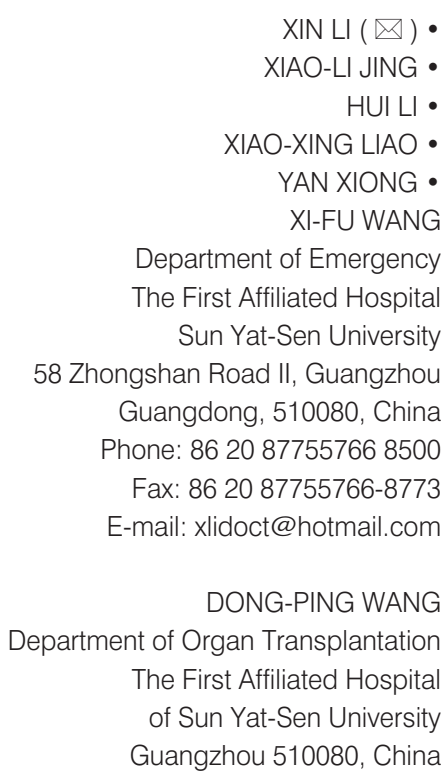

DONG-PING WANG Department of Organ Transplantation The First Affiliated Hospital of Sun Yat-Sen University Guangzhou 510080, China

\begin{abstract}
O bjective. A combination of vasopressin and epinephrine may be more effective than epinephrine alone in cardiopulmonary resuscitation (CPR), but evidence is lacking to make clinical recommendations. This meta-analysis compares the efficacy of vasopressin and epinephrine used together versus epinephrine alone in cardiac arrest (CA).

Methods. We searched MEDLINE and EMBASE for randomized trials comparing the efficacy of vasopressin and epinephrine versus epinephrine alone in adults with cardiac arrest. The primary outcome was the return of spontaneous circulation (ROSC) and the survival rate on admission and discharge. We also analyzed ROSC in subgroups of patients presenting with different arrest rhythms, such as asystole, pulseless electrical activity (PEA), ventricular fibrillation (VF).

Results. We analyzed 6 randomized trials out of 485 articles. We did not find evidence supporting the superio rity of vasopressin and epinephrine used in combination, except for the survival rate at $24 \mathrm{~h} 2.9995 \% \mathrm{Cl}(1.43,6.28)$. No evidence supports the conclusion that vasopressin combined with epinephrine is better than epinephrine alone for RoSC, even amongst subgroups of patients.

Conclusion. This systematic review of the efficacy of vasopressin and epinephrine use found that its combined use is better for $24 \mathrm{~h}$ survival rate but only in one study which included 122 patients. Further investigation will be needed to support the use of this combination for cardiac arrest management.
\end{abstract}

Key words: cardiopulmonary resuscitation, meta-analysis, epinephrine, vasopressin

\section{Introduction}

Survival rates for cardiac arrest patients, both in and out of hospital, are poor. Furthermore, survival without severe neurological impairment has not improved over the past few decades. Epinephrine has been used during cardiopulmonary resuscitation for more than 100 years, (1-3) but has become controversial because it is associated with increased adverse effects.

An increasing body of evidence from laboratory investigations suggests that vasopressin may represent a promising alternative vasopressor for use during cardiac arrest and resuscitation. Several clinical trials have demonstrated superior survival rates with the use of vasopressin instead of epinephrine. $(4,5)$ Recently, the potential benefit of the administration of both drugs has drawn researchers' attention. There have been several human studies in which some patients received both vasopressin and epinephrine. Among those trials, some have reported more desirable outcomes with the administration of both drugs, including increased ROSC and survival rate. (6-8)

The current international guidelines for CPR recommend the use of vasopressin during cardiac resuscitation as 
a secondary alternative. This recommendation could lead to the use of vasopressin for millions of cardiac arrests worldwide. However, some clinical studies yielded contrasting findings. Therefore, our aim was to investigate the effectiveness of vasopressin and epinephrine for the treatment of patients with cardiac arrest.

\section{Materials and methods}

We searched MEDLINE, from January 1966 to December 2008, and EMBASE, from January 1950 to December 2008, for research papers.

Keywords used in this search were [(cardiac arrest) or (cardiopulmonary resuscitation) or (cardiopulmonarycerebral resuscitation)] and [epinephrine or adrenaline] and [vasopressin or argipressin or (antidiuretic hormone)]. In MEDLINE, the search was limited by the search words "Publication Date since 1966/01/01 till 2008/12/31", "English" and "Human". We excluded those research papers with the following keywords: "case reports", " letter", "review", "practice guideline", "review literature", "review of reported cases", "review, academic", "review, multicase", "review, tutorial", "scientific integrity review", "congresses", "interview", "overall", "comment", "news", "newspaper article" and "address". In EMBASE, the search was limited by the search words: "Publication Date since „1950 till 2008", "English” and "Human". The search strategy was reviewed by library personnel to ensure that it was complete. We did not limit the articles published as abstracts only. The references of articles were searched for citations which may have been missed by the electronic search.

Eligible patients had a cardiac arrest and had been treated with CPR. The diagnosis of cardiac arrest and CPR was based on International guidelines. The process of diagnosis and management was registered according to the Utstein model. We looked at randomized trials comparing vasopressin to epinephrine for adults with cardiac arrest. Patients in the treatment groups were those who suffered a cardiac arrest and who had received vasopressin and epinephrine during CPR. The sequences of drug administration were not restricted. Patients in the control groups were those who experienced a cardiac arrest and were treated by CPR with epinephrine alone. Efficacy was compared between the treatment and control groups. The incidence of the ROSC, survival rate at $24 \mathrm{~h}$, survival to hospital admission, survival to hospital discharge and neurologic outcome were recorded.

Odds ratio (OR) and 95\% confidence intervals $(95 \% \mathrm{Cl})$ were calculated for the articles included. Pooled estimates of the odds ratio and $95 \% \mathrm{Cl}$ were obtained by the fixed-effects model of Peto with Review Manager 5.0 software. When there was heterogeneity, OR and $95 \% \mathrm{Cl}$ were obtained by the randomeffect model of Mantel-Haenszel with Review Manager 5.0 software. Publication bias was assessed by Funnel plot.

\section{Results}

The search retrieved 485 papers, and 8 of them were cohort studies on cardiopulmonary resuscitation, vasopressin and epinephrine. Among the 8 articles, one was limited to 10 patients and was published in abstract form only. The reports do not provide detailed information of treatment protocols or its study populations. One of the 8 papers just describes the comparisons of vasopressin and epinephrine for CPR. Two articles were finally excluded from this meta-analysis. Only six cohort studies were included in this meta-analysis to be analyzed for the effect of the association of vasopressin and epinephrine in CPR. Participants and the selected study design characteristics of the six cohort studies included in the metaanalysis are detailed in table 1. (7-12) Finally, the study by Stiell et al. was an in-hospital study in which time to initial drug administration was rapid (1.6min to CPR, 2.8 min to Advanced Cardiovascular Life Support (ACLS)), but the other five studies were out-of-hospital studies. The methodologies for the six studies were deemed too different to be compared and thus a meta-anal- ysis was not attempted to combine in-hospital and out-of-hospital arrests together.

\section{Comparing the outcome of vasopressin and epinep- hrine versus epinephrine alone for CPR}

1. We compared the rate of ROSC between the vasopressin and epinephrine and epinephrine alone groups. The rate of ROSC was compared between two groups in five articles. Among the five articles, none concluded that the combination group did increase the rate of ROSC $(1.05,95 \% \mathrm{Cl}$ $[0.92,1.19])$. This meta-analysis indicates that compared with epinephrine alone, the combination group did not improve outcome (figure 1).

2. We compared the survival rate between the two groups. First, the 24 h survival rate was compared between the two groups. Two articles included and one concluded that patients receiving vasopressin or epinephrine had an improved $24 \mathrm{~h}$ survival rate. Second, three articles compared the survival rate on admission. Two concluded significant differences between the two groups, while the others had contrary results. The last survival rate we compared was the survival on discharge. Five articles did this comparison, with only one finding significant differences. However, a meta-analysis indicates that the combination of vasopressin and epinephrine only significantly improved the $24 \mathrm{~h}$ survival rate $(2.99,95 \% \mathrm{Cl}$ [1.43, 6.28]) (figure 2.1-2.3)

3. We compared the rate of ROSC according to the subgroups of patients with cardiac arrest, selected according to the Utstein Consensus Conference. Subgroup analyses were made between the vasopressin and epinephrine group and epinephrine alone group. Although one out of three included studies revealed that the combination group increased the rate of ROSC among patients with asystole and one of five studies indicated a significant difference in patients with ventricular fibrillation (VF), our meta-analysis did not show a convincing conclusion (1.08 


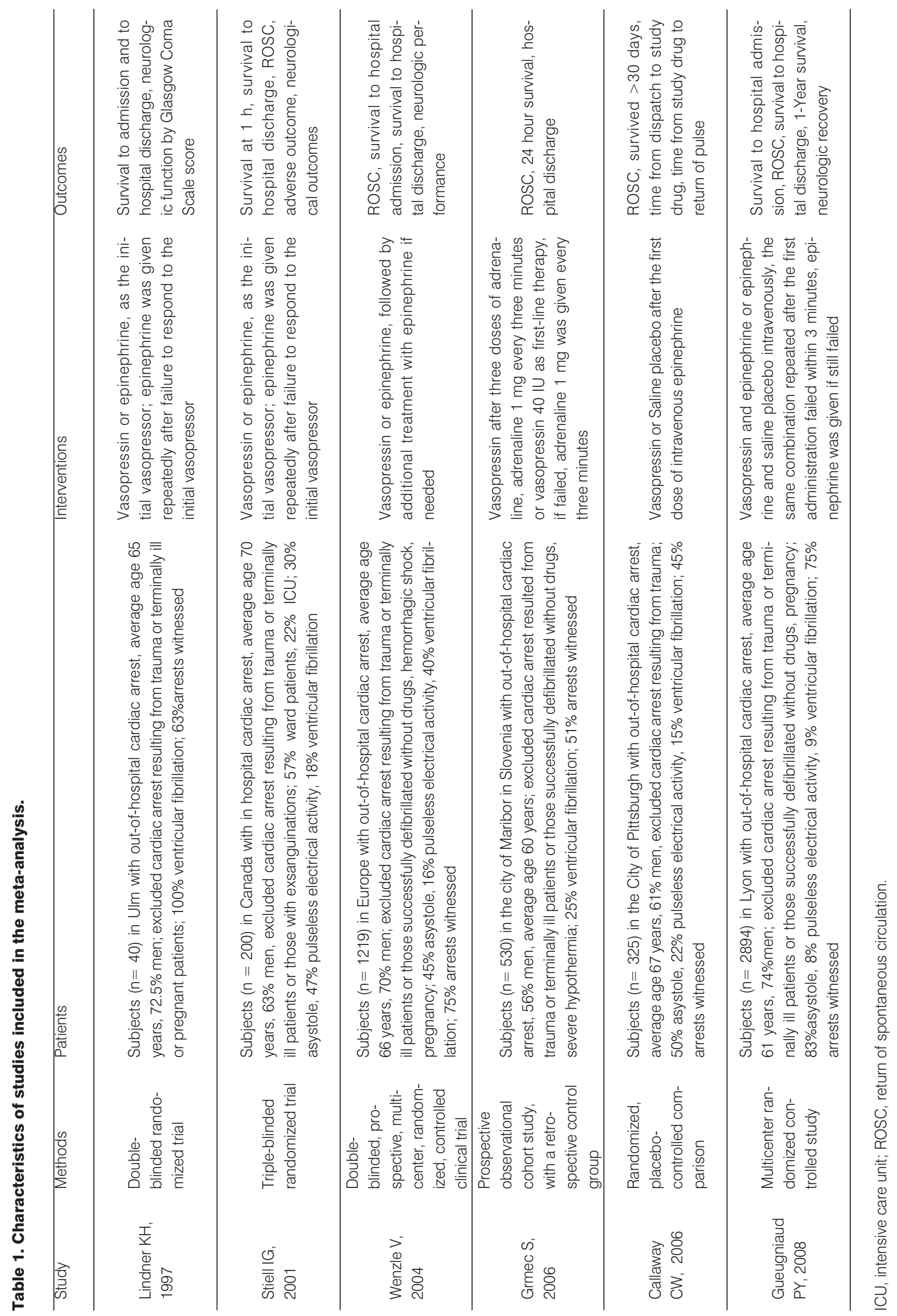


$95 \% \mathrm{Cl}[0.92,1.28]$ and $(0.91,95 \% \mathrm{Cl}$ $[0.61,1.35]))$. When pulseless electrical activity (PEA) was the initial rhythm, ROSC did not differ between groups in our meta-analysis $(1.32,95 \% \mathrm{Cl}[0.98$, 1.79]) (figure 3.1-3.3).

\section{Potential Publication Bias}

Potential publication bias (for the primary endpoint) was based on visual analysis of the funnel plot. The distribution is roughly symmetrical; thus, there is no strong evidence of publication bias (figure 4).

\section{Discussion}

For patients in cardiac arrest, administration of epinephrine appears to increase myocardial oxygen demand and consumption, decreases myocardial adenosine triphosphate (ATP) with pro-arrhythmic effects, and increases myocardial lactate levels. (13-17) It may cause severe tachycardia immediately after ROSC, $(18,19)$ and the most serious side effect of epinephrine is the increase in myocardial oxygen consumption during VF and myocardial dysfunction in the post-resuscitation phase. (20) The recently published European Resuscitation Council CPR Guidelines state that 'current evidence is insufficient to support or refute the routine use of any particular drug or sequence of drugs'; the respective CPR algorithm primarily recommends injection of $1 \mathrm{mg}$ epinephrine every 3-5 minutes, while vasopressin may also be injected. (21) In contrast, the approach of the American Heart Association CPR guidelines is more liberal, stating that 'one dose of vasopressin may replace either the first or second dose of epinephrine'. (22)

Vasopressin has been shown to increase coronary perfusion pressure and brain perfusion more effectively than epinephrine. $(4,23)$ Since it was found that endogenous vasopressin levels in successfully resuscitated patients were significantly higher than levels in patients who died, (2) it was postulated that it might be beneficial to administer vasopressin during CPR. Other properties unique to vasopressin may also

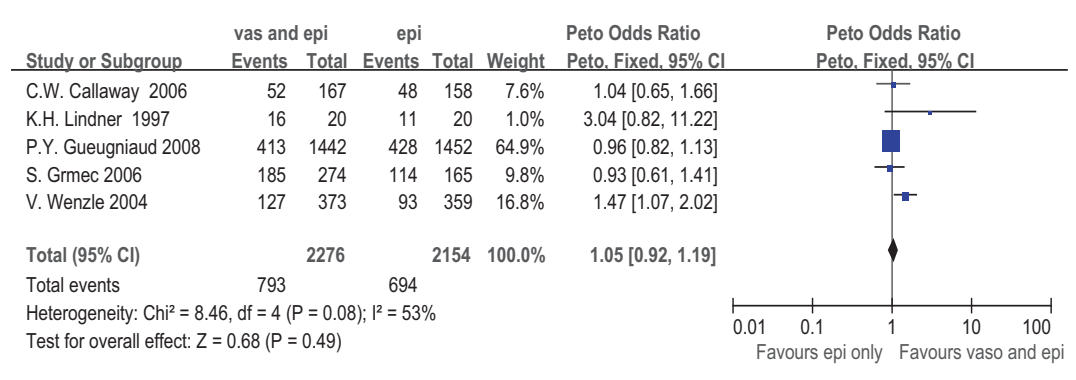

Figure 1. Return of spontaneous circulation.

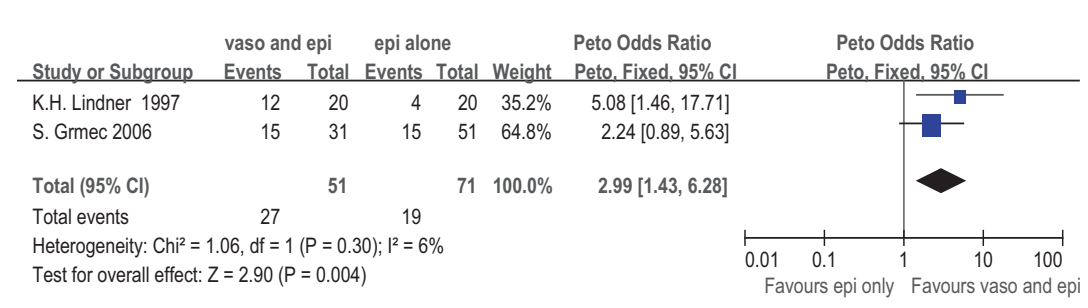

Figure 2.1. Survival rate at $24 \mathrm{~h}$.

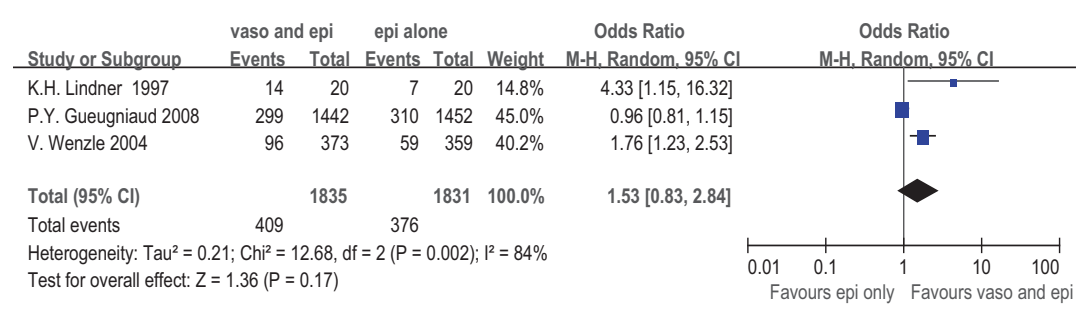

Figure 2.2. Survival rate on admission.

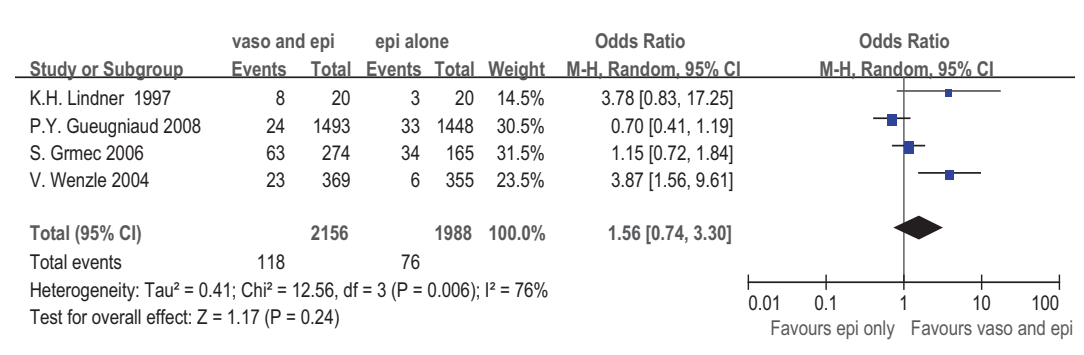

Figure 2.3. Survival rate at discharge.

contribute to its synergistic effects with epinephrine. The V2 receptor vasodilatory activity of vasopressin may mitigate end organ hypoperfusion that results from multiple doses of epinephrine. (21) Combining both drugs may combine both beneficial effects and avoid complications of injecting excessive dosages of one drug alone. In a series of animal studies, the group of subjects that received vasopressin and epinephrine appeared to have a more rapid rise in coronary perfusion pressure, (24) higher levels of left ventricular myocardial blood flow during CPR, (25) higher resuscitation rates, and improved cerebral blood flow $(25,26,27)$ than the group that received epinephrine 


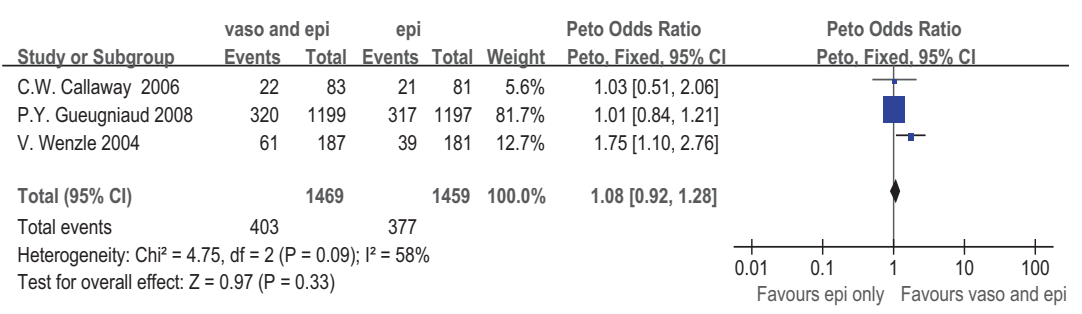

Figure 3.1. Return of spontaneous circulation following asystole.

\begin{tabular}{|c|c|c|c|c|c|c|c|c|c|}
\hline \multirow[b]{2}{*}{ Study or Subgroup } & \multicolumn{2}{|c|}{ vaso and epi } & epi & \multirow[t]{2}{*}{ Total } & \multirow{2}{*}{ Weight } & \multirow{2}{*}{$\begin{array}{l}\text { Peto Odds Ratio } \\
\text { Peto, Fixed, } 95 \% \mathrm{Cl}\end{array}$} & \multirow{2}{*}{\multicolumn{2}{|c|}{$\begin{array}{l}\text { Peto Odds Ratio } \\
\text { Peto, Fixed, } 95 \% \mathrm{Cl}\end{array}$}} & \\
\hline & Events & Total & Events & & & & & & \\
\hline C.W. Callaway 2006 & 12 & 36 & 13 & 36 & $16.9 \%$ & $0.89[0.34,2.32]$ & & & \\
\hline P.Y. Gueugniaud 2008 & 50 & 111 & 60 & 120 & $59.0 \%$ & $0.82[0.49,1.37]$ & & & \\
\hline V. Wenzle 2004 & 18 & 64 & 14 & 56 & $24.1 \%$ & $1.17[0.52,2.63]$ & & & \\
\hline Total $(95 \% \mathrm{Cl})$ & & 211 & & 212 & $100.0 \%$ & $0.91[0.61,1.35]$ & & & \\
\hline Total events & 80 & & 87 & & & & & & \\
\hline Heterogeneity: $\mathrm{Chi}^{2}=0$. &,$d f=2(P$ & $=0.77$; & $P^{2}=0 \%$ & & & & 0.01 & 0.1 & 100 \\
\hline
\end{tabular}

Figure 3.2. Return of spontaneous circulation following pulseless electrical activity.

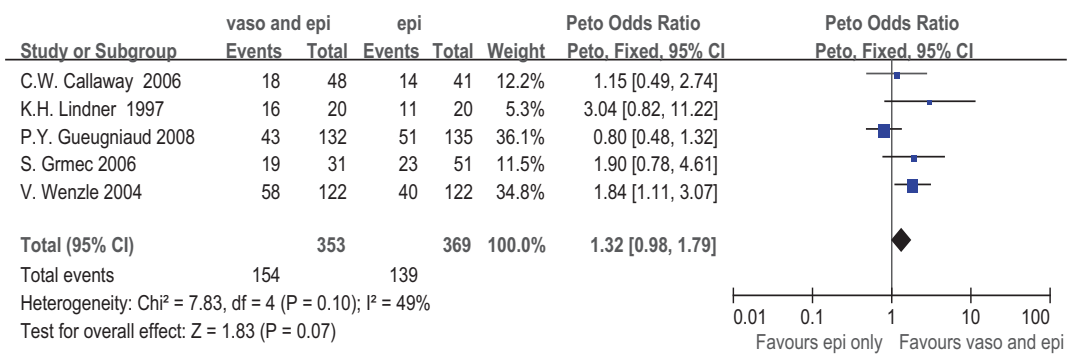

Figure3.3. Return of spontaneous circulation following ventricular fibrillation.

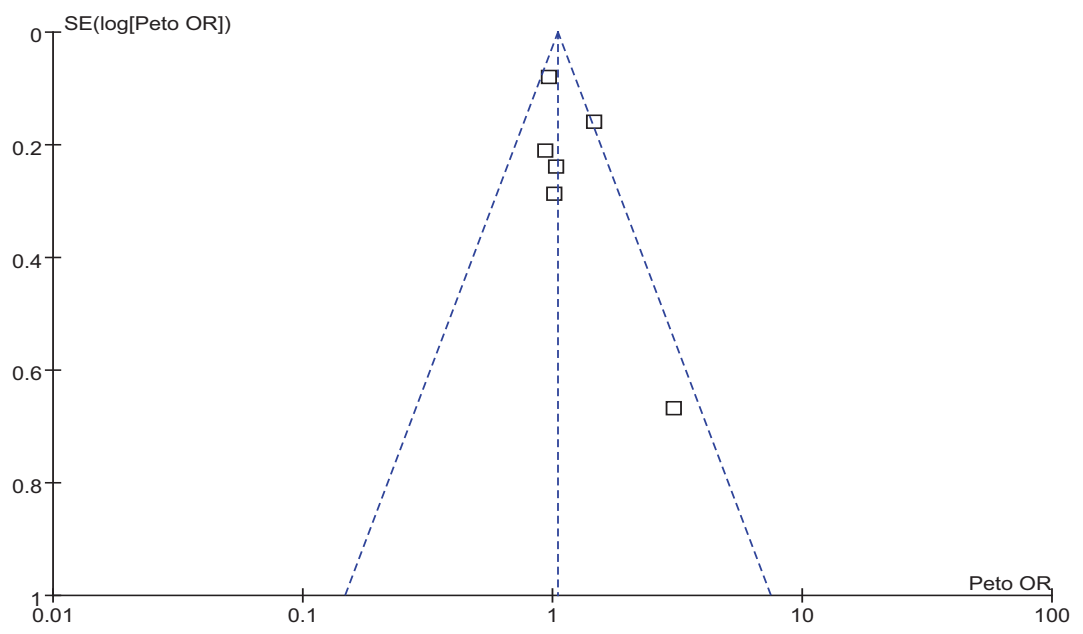

Figure 4. Funnel plot of all studies included in the meta-analysis. only, perhaps because of a synergistic effect of epinephrine and vasopressin. (28-30)

Two previous meta-analyses have investigated whether vasopressin is superior to epinephrine in the management of cardiac arrest. The first, which included 2 human studies and 33 animal studies published before 2003, found vasopressin equivalent to epinephrine in humans, but significantly superior to epinephrine in animals. (31) In a second meta-analysis, which included 5 human studies, the investigators concluded that there is no clear advantage of vasopressin over epinephrine in the treatment of cardiac arrest in regard to failure of ROSC, hospital admission, hospital discharge and survival rates at 24 hours. And in the secondary analysis, subgroup analysis based on initial cardiac rhythm showed no statistically significant difference. (5) Another meta-analysis of the combination of vasopressin and epinephrine versus repeated doses of epinephrine alone , which included 3 studies, found trends towards better ROSC but equivocal effects on survival. (32)

Our results, which include not only ROSC, hospital admission, hospital discharge and survival rates in the first 24 hours, but also subgroups based on initial cardiac rhythm, provide the best available estimates of efficiency between the addition of vasopressin to epinephrine and epinephrine alone. Despite the sensitivity of the search strategy used and the large number of published papers on this subject (485 studies), only six trials satisfied the strict inclusion criteria. In contrast to findings regarding patients with ventricular fibriIlation, pulseless electrical activity or asystole, $(4,10,23,33-34)$ the results of clinical trials did not support the addition of vasopressin to epinephrine in cardiac arrest resuscitation, except in a subgroup looking at survival rate at $24 \mathrm{~h}$. For in- hospital patients, the vasopressin and epinephrine group failed to show any improvement compared with epinephrine for either $1 \mathrm{~h}$ survival or survival to hospital discharge. The combination of epinephrine and vaso- 
pressin was not shown to be better than epinephrine alone. Although vasopressin is banked in a Class Ilb recommendation in cardiac arrest that requires fair-to-good evidence with a majority of experts considering it an 'optional or alternative intervention', there is insufficient evidence to advocate the use of vasopressin plus epinephrine in CPR temporally.

This meta-analysis has some limitations. Firstly, we included three trials in the analysis that had recruited a small proportion of patients (about 7\%) who had experienced CPR. Exclusion of these trials did not affect the outcome of our analysis apparently. Secondly, the dose and the sequence of the two drugs differed between included trials. Thirdly, the included trials represented participants with a clinically heterogeneous level of risk (although statistical heterogeneity was (ow), which was directly related to the method of selection of the comparison group in each study. As has been reported, the funnel plots showed a relatively symmetric distribution, but the point cloud did not have a distinctive funnel form. This was probably due to the relatively high heterogeneity and to the small number of primary studies included in the meta-analysis. Therefore a publication bias may have also occurred. The majority of the included studies were performed at single sites, so therefore same staff could have treated both cases and controls with a possible contamination bias.

\section{Conclusion}

We failed to detect a trend favoring the combination of vasopressin and epinephrine, except for the survival rate at 24h. However, only 122 patients in two studies were involved in this comparison. We have no idea whether a proposal of the use of vasopressin and epinephrine should be recommended, unless further large randomized controlled trials show more evidence of improved outcome. There is a need for randomized controlled trials (RCTs) to evaluate the addition of vasopressin to epinephrine in cardiac arrest. However, there is no adequate evidence to advocate the use of epinephrine plus vasopressin for cardiac arrest at this point in time.

\section{ACKNOWLEDGMENTS}

This study was supported by the Science and Technology Foundation of Guangdong Province of China grants: (2006B36004010) and (2007B031402005).

\section{REFERENCES}

1. Paradis NA, Koscove EM. Epinephrine in cardiac arrest: a critical review. Ann Emerg Med 1990 Nov;19(11):1288-301.

2. Barlow M. Vasopressin. Emerg Med (Fremantle) 2002 Sep;14(3):304-14.

3. Garcia-Villalon AL, Garcia JL, Fernandez N, Monge L, Gomez B, Dieguez G. Regional differences in the arterial response to vasopressin: role of endothelial nitric oxide. Br J Pharmacol 1996 Aug;118(7):1848-54.

4. Wenzel V, Lindner KH, Krismer AC, Miller EA, Voelckel WG, Lingnau W. Repeated administration of vasopressin but not epinephrine maintains coronary perfusion pressure after early and late administration during prolonged cardiopulmonary resuscitation in pigs. Circulation 1999 Mar 16;99(10):1379-84.

5. Aung K, Htay T. Vasopressin for cardiac arrest: a systematic review and meta-analysis. Arch Intern Med 2005 Jan 10;165(1):17-24.

6. Lindner KH, Prengel AW, Brinkmann A, Strohmenger HU, Lindner IM, Lurie KG. Vasopressin administration in refractory cardiac arrest. Ann Intern Med 1996 Jun 15;124(12):1061-4.

7. Wenzel V, Krismer AC, Arntz HR, Sitter H, Stadlbauer KH, Lindner KH. A comparison of vasopressin and epinephrine for out-of-hospital cardiopulmonary resuscitation. N Engl J Med 2004 Jan 8;350(2):105-13.

8. Grmec S, Mally S. Vasopressin improves outcome in out-of-hospital cardiopulmonary resuscitation of ventricular fibrillation and pulseless ventricular tachycardia: a observational cohort study. Crit Care 2006 Feb;10(1):R13.

9. Stiell IG, Hebert PC, Wells GA, Vandemheen KL, Tang AS, Higginson LA, et al. Vasopressin versus epinephrine for inhospital cardiac arrest: a randomised controlled trial. Lancet 2001 Jul 14;358(9276):105-9.

10. Lindner KH, Dirks B, Strohmenger HU, Prengel AW, Lindner IM, Lurie KG. Randomised comparison of epinephrine and vasopressin in patients with out-of-hospital ventricular fibrillation. Lancet 1997 Feb 22;349(9051):535-7.

11. Callaway CW, Hostler D, Doshi AA, Pinchalk M, Roth RN, Lubin J, et al. Usefulness of vasopressin administered with epinephrine during out-of-hospital cardiac arrest. Am J Cardiol 2006 Nov 15;98(10):1316-21.

12. Gueugniaud PY, David JS, Chanzy E, Hubert H, Dubien PY, Mauriaucourt P, et al. Vasopressin and epinephrine vs. epinephrine alone in cardiopulmonary resuscitation. N Engl J Med 2008 Jul 3;359(1):21-30. 
13. Ditchey RV, Lindenfeld J. Failure of epinephrine to improve the balance between myocardial oxygen supply and demand during closedchest resuscitation in dogs. Circulation 1988 Aug;78(2):382-9.

14. Tang W, Weil MH, Sun S, Noc M, Yang L, Gazmuri RJ. Epinephrine increases the severity of postresuscitation myocardial dysfunction. Circulation 1995 Nov 15;92(10):3089-93.

15. Thrush DN, Downs JB, Smith RA. Is epinephrine contraindicated during cardiopulmonary resuscitation? Circulation 1997 Oct 21;96(8):2709-14.

16. Paradis NA, Wenzel V, Southall J. Pressor drugs in the treatment of cardiac arrest. Cardiol Clin 2002 Feb;20(1):61-78.

17. Wayne MA, Racht EM, Aghababian RV, Kudenchuk PJ, Ornato JP, Slovis CM. Prehospital management of cardiac arrest: how useful are vasopressor and antiarrhythmic drugs? Prehosp Emerg Care 2002 Jan;6(1):72-80.

18. Livesay JJ, Follette DM, Fey KH, Nelson RL, DeLand EC, Barnard RJ, et al. Optimizing myocardial supply/demand balance with alphaadrenergic drugs during cardiopulmonary resuscitation. J Thorac Cardiovasc Surg 1978 Aug;76(2):244-51.

19. Midei MG, Sugiura S, Maughan WL, Sagawa K, Weisfeldt ML, Guerci AD. Preservation of ventricular function by treatment of ventricular fibrillation with phenylephrine. J Am Coll Cardiol 1990 Aug;16(2):489-94.

20. Lurie KG, Lindner KH. Recent advances in cardiopulmonary resuscitation. J Cardiovasc Electrophysiol 1997 May;8(5):584-600.

21. Nolan JP, Deakin CD, Soar J, Bottiger BW, Smith G. European Resuscitation Council guidelines for resuscitation 2005. Section 4. Adult advanced life support. Resuscitation 2005 Dec;67 Suppl 1:S39-S86.

22. 2005 American Heart Association Guidelines for Cardiopulmonary Resuscitation and Emergency Cardiovascular Care. Circulation 2005 Dec 13;112(24 Suppl):IV1-203

23. Lindner KH, Prengel AW, Pfenninger EG, Lindner IM, Strohmenger HU, Georgieff M, et al. Vasopressin improves vital organ blood flow during closed-chest cardiopulmonary resuscitation in pigs. Circulation 1995 Jan 1;91(1):215-21.

24. Mulligan KA, McKnite SH, Lindner KH, Lindstrom PJ, Detloff B, Lurie KG. Synergistic effects of vasopressin plus epinephrine during cardiopulmonary resuscitation. Resuscitation 1997 Nov;35(3):265-71.

25. Lurie KG, Voelckel WG, Iskos DN, McKnite SH, Zielinski TM, Sugiyama A, et al. Combination drug therapy with vasopressin, adrenaline (epinephrine) and nitroglycerin improves vital organ blood flow in a porcine model of ventricular fibrillation. Resuscitation 2002 Aug;54(2):187-94.

26. Mayr VD, Wenzel V, Voelckel WG, Krismer AC, Mueller T, Lurie KG, et al. Developing a vasopressor combination in a pig model of adult asphyxial cardiac arrest. Circulation 2001 Oct 2;104(14):1651-6.

27. Voelckel WG, Lurie KG, McKnite S, Zielinski T, Lindstrom P, Peterson C, et al. Effects of epinephrine and vasopressin in a piglet model of prolonged ventricular fibrillation and cardiopulmonary resuscitation. Crit Care Med 2002 May;30(5):957-62.

28. Guyette FX, Guimond GE, Hostler D, Callaway CW. Vasopressin administered with epinephrine is associated with a return of a pulse in out-of-hospital cardiac arrest. Resuscitation 2004 Dec;63(3):277-82.

29. Wenzel V, Linder KH, Augenstein S, Prengel AW, Strohmenger HU. Vasopressin combined with epinephrine decreases cerebral perfusion compared with vasopressin alone during cardiopulmonary resuscitation in pigs. Stroke 1998 Jul;29(7):1462-7.

30. Biondi-Zoccai GG, Abbate A, Parisi Q, Agostoni P, Burzotta F, Sandroni C, et al. Is vasopressin superior to adrenaline or placebo in the management of cardiac arrest? A meta-analysis. Resuscitation 2003 Nov;59(2):221-4.

31. Sillberg VA, Perry JJ, Stiell IG, Wells GA. Is the combination of vasopressin and epinephrine superior to repeated doses of epinephrine alone in the treatment of cardiac arrest-a systematic review. Resuscitation 2008 Dec;79(3):380-6.

32. Prengel AW, Lindner KH, Keller A. Cerebral oxygenation during cardiopulmonary resuscitation with epinephrine and vasopressin in pigs. Stroke 1996 Jul;27(7):1241-8.

33. Wenzel V, Lindner KH, Prengel AW, Maier C, Voelckel W, Lurie KG, et al. Vasopressin improves vital organ blood flow after prolonged cardiac arrest with postcountershock pulseless electrical activity in pigs. Crit Care Med 1999 Mar;27(3):486-92.

34. Wenzel V, Lindner KH, Krismer AC, Voelckel WG, Schocke MF, Hund W, et al. Survival with full neurologic recovery and no cerebral pathology after prolonged cardiopulmonary resuscitation with vasopressin in pigs. J Am Coll Cardiol 2000 Feb;35(2):527-33. 